\title{
TREATMENT OF ESTABLISHED SYMBLEPHARON WITH SPLIT SKIN HOMOGRAFT*
}

\author{
BY
}

\author{
G. J. ROMANES
}

From the Corneo-Plastic Unit and Eye Bank, Queen Victoria Hospital, East Grinstead, Sussex

THE condition of symblepharon is caused by the union of two opposing raw $\overrightarrow{\vec{\omega}}$ surfaces in the fornix between the lids and the globe of the eye following trauma or disease in the region. The traumatizing agents are most commonly thermal burns from boiling or exploding metal or chemical burns from lime and allied substances insufflated to the eye accidentally in the course of industrial processes.

The effects of the condition in the absence of corneal scarring are due to inadequate globe movements and are manifest to the patient as diplopia. $\frac{D}{0}$ More often the sight is impaired by corneal opacity and there is also some discomfort and watering of the eye and inability to move the lids or close them properly. The scar tissue also carries a vascular supply which runs on to the cornea and prevents effective keratoplasty without preliminary treatment.

The treatment of the condition is surgical and the methods used hitherto have not been altogether satisfactory. The aim is to divide the symblepharon and to prevent the reformation of scar tissue during the healing period. The new scar tissue, if allowed to develop, in time causes another symblepharon as extensive as its predecessor. The formation of scar tissue is prevented by the provision of cover for the raw area. In the past this has been done by local plastic procedures-a single pedicle conjunctival flap from above the limbus to the inferior fornix, where it is secured in position by sutures under tension. Alternatively, the defect was covered by a free graft of mucous membrane from the mouth, or by a split skin graft. The disadvantages of the first method are:

(i) There may not be sufficient conjunctiva available to provide all the cover required without suturing under tension.

(ii) If the flap is secured in this manner there is a great increase in the tendency to scar formation and to slow healing of the wound with its consequent disability.

(iii) The conjunctiva itself may be considerably scarred, so that there is also much shrinkage.

(iv) It may not be desirable for subsequent projected surgery to produce scarring all round the limbus.

* Received for publication November 11, 1952. 
Mucous membrane grafts are bulky and unsightly. They can only be placed inside the lid and consequently their field of usefulness is limited.

Split skin grafts are rarely used in the presence of an eye because they shrink so extensively during the healing period. A socket which has been treated with skin grafts often has a great deal of discharge and desquamation which is a constant trouble to maintain under hygienic control.

It seemed possible that these difficulties would be overcome, at least in part, by using skin from another individual in the form of a free Thiersch craft to cover the bare area produced by the surgical manoeuvres. It is known that the skin does not survive for long so that it can cause none of the troubles mentioned above. When it sloughs off the process is gradual and there is no bare area exposed because the conjunctiva grows in to provide cover at the same rate as the exposure takes place.

\section{Technique}

The operation consists in incising the symblepharon at its attachment to the globe and separating it from the sclera and episcleral layers, from the limbus into the fornix. The globe is then rotated so as to produce as large a bare area as possible and to ensure that movement is perfectly free. The next step is to determine the size and shape of the defect. This is done by impressing upon it a piece of sterile Jaconet and obtaining a bloodstained "map". This is used as a pattern to shape the graft of stored skin by cutting with scissors round the periphery of a stored-skin sample which has been spread upon Tulle Gras with the "map" superimposed upon it so that the nutrient surface of the graft will be facing towards the bare area. A graft of the exact shape and size of the defect is thus obtained. Unless this procedure is followed accurately the graft is of the wrong shape, and that makes the subsequent stage of suturing more difficult. The graft is then set into place with edge-to-edge apposition between it and the host epithelium all round its periphery, using 00 black silk interrupted sutures. The graft bed is washed free of clots using a lacrimal cannula on a syringe with normal saline. The patency of the fornix is maintained throughout the healing period by the insertion of a mattress suture over a short piece of No. 6 Jacques rubber catheter. The suture is tied out on to the cheek over rubber buttons to prevent possible pressure necrosis of the skin.

In the post-operative period both eyes are bandaged for 5 days to allow the graft to take. After this time the first dressing is done and the sutures removed; full movement of the eye is encouraged from then on.

We have always used general anaesthesia at this Unit but there is no contraindication to local infiltration and drops.except the well-known difficulty of effectively anaesthetizing scar tissue. All donor skin is taken from patients with a known negative Wassermann reaction. The period of storage seems to be of little consequence; if the skin is stored for periods of 6 to 8 weeks in a refrigerator, a temperature of plus $4^{\circ} \mathrm{C}$. is essential. The skin is wrapped in sterile damp gauze after being spread on tulle gras and kept in glass jars for use. For shorter periods a cool, sterile place is required, preferably a glass jar in a refrigerator. There is no contraindication to direct use, the skin being taken from one theatre and used almost immediately in an adjacent one. Skin has been used from donors ranging from 9 to 60 years of age. 


\section{Case Reports}

(1) Aged 9 years.-1947. Hydrochloric acid burn with destruction of right globe retained 을

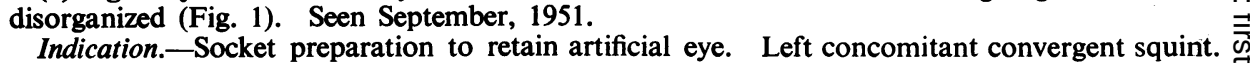

Inadequate lower fornix. Movements of globe restricted.

3.9.51. Operation. Stored Thiersch skin 6 weeks old.

7.9.51. Complete take.

12.9.51. All skin in place, no stain with fluorescein (Fig. 2), no symblepharon, no skin visible, eye quiet, deep fornix (Fig. 3)

Operation. Squint correction, deep fornix as before (Fig. 4).

FIG. 1.-Case 1, as seen initially.

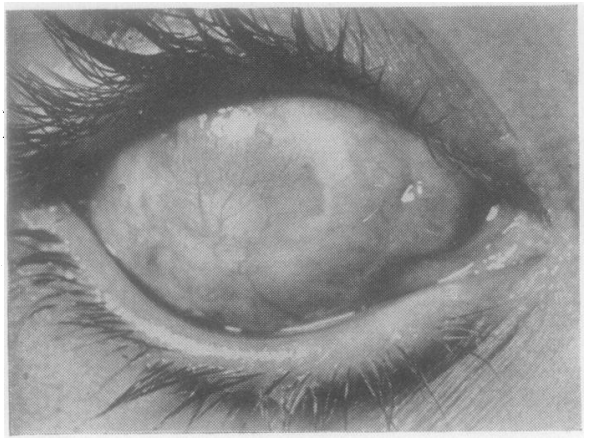

Fig. 3.-Case 1, fornix after disappearance of graft.

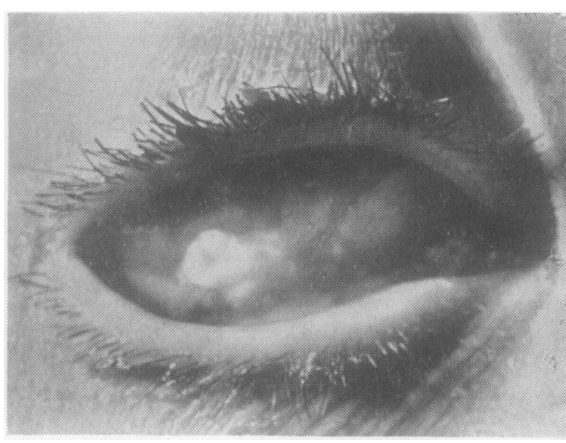

FIG. 2.-Case 1, homograft of skin in place and viable.

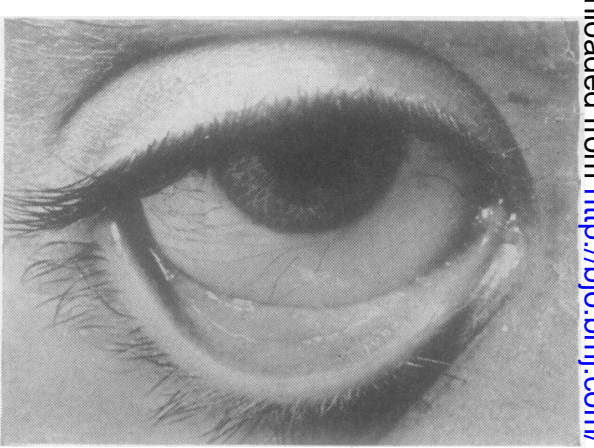

FIG. 4.-Case 1, artificial eye in place, lid pulled down to show lower fornix.

(2) Aged 24 years. - 1949. Sulphuric acid burn left upper lid pars lacrimalis. Traumatic pterygium. Restricted movements (Fig. 5, opposite).

Indication.-Preparation for keratoplasty.

11.12.51. Operation.

17.12.51. Stitches out, movements full; skin viable beyond margin of raw area, deep fornix (Fig. 6, opposite).

31.12.51. No skin remaining, full movements of globe, no stain with fluorescein.

24.3.52. Full movements of globe, normal fornix (Fig. 7, opposite).

(3) Aged 18 years.-1950. Metal burn in left eye September 7 (Fig. 8, opposite).

Indication.-Preparation for keratoplasty.

8.1.51. Division of symblepharon and mucous membrane graft; fornix depth unchanged with some ectropion. 


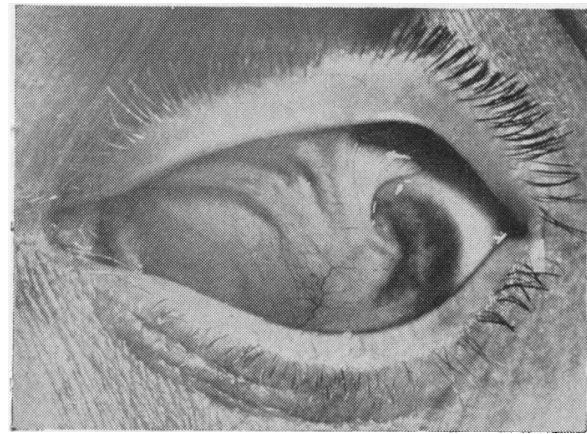

FIG. 5.-Case 2, as seen initially.

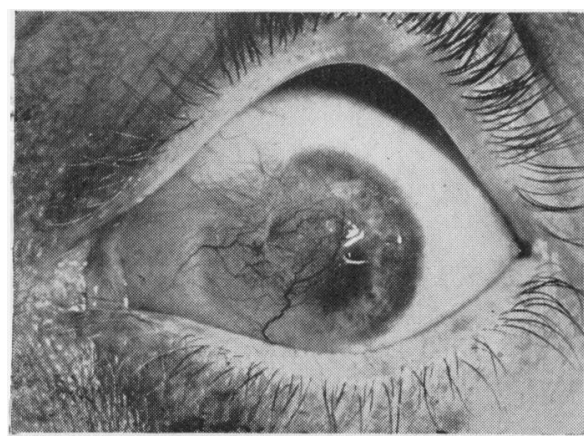

Fig. 7.-Case 2, end-result of symblepharon repair before keratoplasty

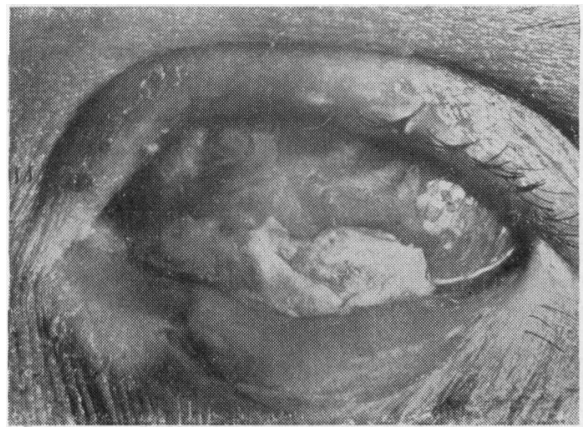

Fig. 9.-Case 3, homograft of skin in place and viable.

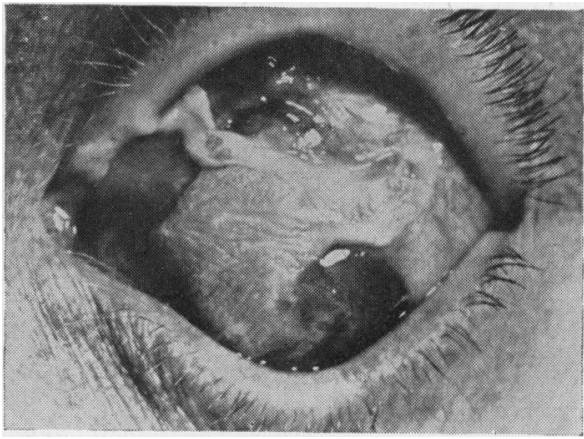

FIG. 6.-Case 2, homograft of skin in place and viable.

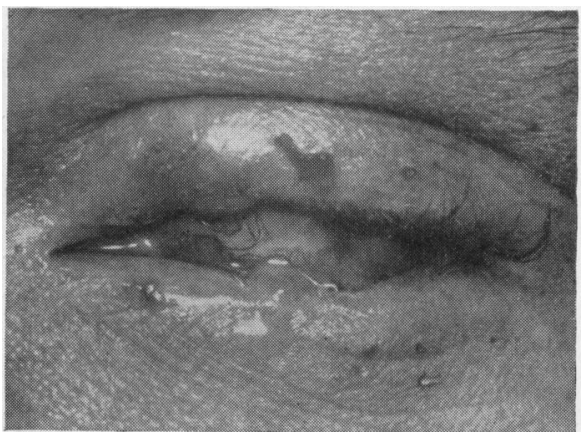

Fig. 8.-Case 3, as seen initially.

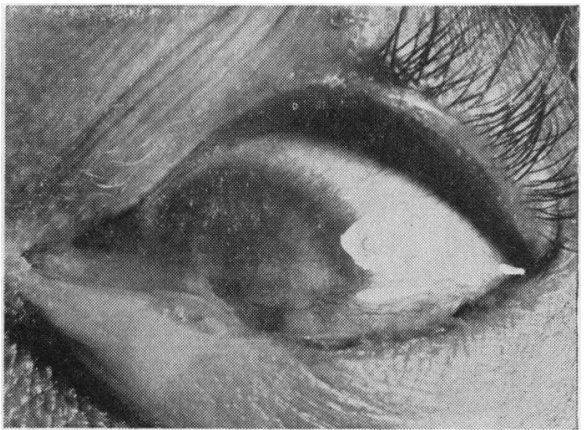

FIG. 10.-Case 3, end-result of symblepharon repair before keratoplasty.

5.3.51. Correction of ectropion of graft by conjunctival plastic. Result: no depth to fornix. 23.5.51. Operation. Division of symblepharon and insertion of contact glass. Result: no depth to fornix.

1.10.51. Division of symblepharon stored skin graft. Result: good fornix, still old ectropion. (Fig. 9).

5.5.52. No skin left. Eye healed. Fornix deep. Movements of globe full (Fig. 10). 
(4) Aged 68 years.-Solder exploded 47 years ago.

Indication.-Preparation for keratoplasty.

12.2.52. Operation. Division of symblepharon L. Stored skin inserted over contact glass.

24.2.52. Skin alive and healthy, good deep fornix.

30.5.52: All skin gone, fornix satisfactory.

(5) Aged 39 years.-1949. Incendiary bomb incident.

Indication.-Preparation for keratoplasty. Seen August, 1951, through stages of final repair.

February 1952. Operation. Traumatic pterygium treated MacReynolds, corneal bare area covered by homograft.

27.2.52. Corneal cover satisfactory.

11.7.52. No sign of graft, movements of globe free, awaiting keratoplasty.

(6) Aged 27 years.-April 1950. Metal burn right eye; treated with amnion graft; result symblepharon.

October 1950. Mucous membrane graft to lower fornix: result, shallow fornix, and graft overlying cornea (Fig. 11).

Indication.-Preparation for keratoplasty.

7.3.51. Seen as out-patient.

7.4.52. Operation, excision of mucous membrane graft, refashioning of inferior fornix and grafting with split skin homograft.

14.4.52. Discharged home with skin viable and in place.

12.5.52. See as out-patient, no skin left, fornix satisfactory.

22.8.52. Movements of eye full, fornix satisfactory (Fig. 12).

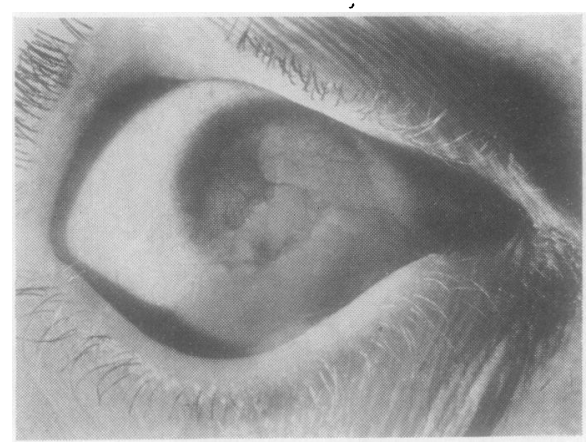

FIG. 11.-Case 6, as seen initially.

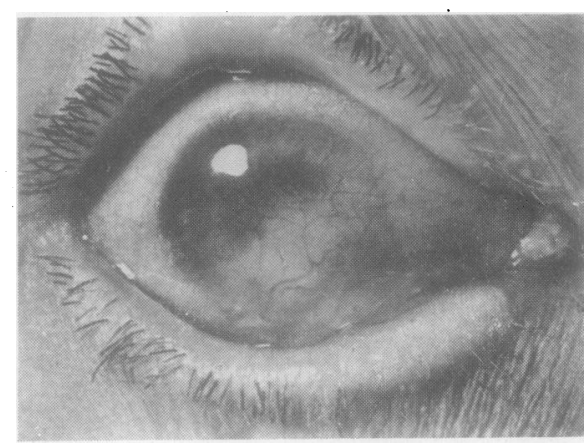

FIG. 12.-Case 6, end-result of symblepharon repair before keratoplasty. Note eversion possible to show fornix depth.

(7) Aged 52 years. - Lime burn both eyes at age of 6 years. 'Not seen until 28.3.52. Indication.-Preparation for keratoplasty.

29.7.52. Operation, division of symblepharon and grafting with split skin homograft.

12.9.52. Inferior fornix free, movements of eye full.

(8) Aged 6 years.-May 1951. Lime burn of right eye. Treated with amniotic membrane graft, result, extensive symblepharon and corneal destruction.

26.6.52. Seen total symblepharon of lower lid on right side.

Indication.-Preparation for retention of prosthesis.

13.9.52. Operation, division of symblepharon and grafting with split skin homograft.

5.10.52. Complete take of graft.

11.10.52. Skin starting to slough, movements of globe satisfactory, fornix depth satisfactory, discharged home.

(9) Aged 29 years.-May 1949. Bilateral lime burns, left eye enucleated because of total destruction. Right eye showed gross destruction of cornea and conjunctiva.

Indication.-Preparation for keratoplasty. 
March, 1952. Seen, almost total symblepharon of upper lid'with corneal destruction and infiltration with vessels.

15.7.52. Operation, division of symblepharon and grafting with homograft.

22.7.52. Full movements, graft in place.

29.9.52. Seen as out-patient, no skin in place, fornix satisfactory, movements of eye full.

(10) Aged 53 years.--January 1952. Molten metal burn of both eyes.

Indication.-Preparation for keratoplasty.

10.6.52. Operation, division of symblepharon and homograft to defect.

27.6.52. Homograft being shed.

11.7.52. No sign of homograft, inferior fornix deep.

26.9.52. Homo skin graft to upper fornix after symblepharon division.

5.10.52. All graft shed, eye quiet, movements good, superior fornix deep, awaiting keratoplasty.

The use of homografts which survive 2 to 3 weeks thus overcomes many difficulties encountered hitherto in the surgery of established symblepharon. The graft is of the right thickness and is easily obtained in adequate quantity. There is no ultimate discharge and no long-term cosmetic factor to be considered in planning the operation. The graft can be set, therefore, upon the best functional site. It is easy to manipulate at operation and is of satisfactory origin. The grafted eyes are quiet in the post-operative and subsequent period. The final healing in the cases treated is completed in a short time and is associated with the minimum of scar-tissue formation. This is due to the very rapid proliferation of the conjunctiva which, combined with the small size of the site, keeps the surface of the whole bare area covered during the necrotic stage. Any scar tissue which forms lies upon the sclera or episclera which is quite able to withstand the shrinking stages. This position also allows for full movement of the lid and obviates all tendency to loss of fornix depth.

It is probable that the repair described is unusual in surgery, since reference to the literature on homografts shows that hitherto the authors have all been concerned to discover and eliminate the factors which lead to the death 'of the graft in order to obtain permanent and stable survival.

\section{Summary}

A satisfactory method of surgical repair of traumatic symblepharon using stored homografts of skin is described in ten cases and photographs.

I wish to acknowledge with gratitude the help I have had in the preparation of this paper from Mr. B. W. Rycroft, Surgeon to the Corneo-Plastic Unit. I am indebted to Mr. L. Schofield for much information on homograft behaviour and to him and colleagues of the surgical staff of the Plastic and Jaw Unit for the provision of skin without which the method could not have been tried. I also wish to thank Mr. Gordon Clemetson for the photographs.

\section{REFERENCE}

Spaeth, E. B. (1948). "Principles and Practice of Ophthalmic Surgery ”, 4th ed., p. 529. Kimpton, London. 